\title{
Is it good to be bad or bad to be good? Assessing the aggregate impact of abnormal weather on consumer spending
}

\author{
Anna Pauliina Sandqvist ${ }^{1} \cdot$ Boriss Siliverstovs $^{2,3}$
}

Received: 24 March 2020 / Accepted: 18 December 2020 / Published online: 3 February 2021

(c) The Author(s) 2021

\begin{abstract}
Although the influence of exceptional weather on individual behaviour has already been acknowledged in finance, psychology, and marketing, the literature examining weather effects at more aggregate level is still limited. Further, there is a lot of anecdotal evidence that weather anomalies affect consumer spending and retail business. The main aim of this analysis is to investigate and quantify the effects of unusual weather in consumer spending at macro-level. Using aggregate retail sales data for Switzerland, our findings reveal that weather deviations from seasonal norms, especially, unusually high or low temperatures in a given month, do cause sizeable intertemporal shifts in consumer spending at country level. Furthermore, the effects of abnormal weather are found to differ across seasons, both with respect to sign and magnitude. In particular, our findings indicate that weather effects manifest mainly through the seasons change channel: weather conditions in line with the coming season boost the purchases early in the season.
\end{abstract}

Keywords Consumer spending · Intertemporal shifts $\cdot$ Retail sales $\cdot$ Unusual weather

JEL Classification E21 $\cdot$ E32 $\cdot$ D12 $\cdot$ C22

There are not as many well-documented, quantified relationships between weather events and economically important activities as one would think existed.

McQuigg (1972)

Ideally, economic analysts would be able to look past the gyrations in the data that are caused by the weather. Unfortunately, this rarely seems to be the case. Most economists jump on the latest numbers and seem to lose sight of context.

Baker (2012).

We thank Klaus Abberger, Jan-Egbert Sturm and the participants of the KOF Brown Bag seminar, the 18th IWH-CIREQ-GW Macroeconometric Workshop and EEA 2018 for the comments and discussions. We thank MeteoSwiss for providing us with the access to the weather data. All remaining errors are of the authors. The opinions expressed here are the authors', and they do not necessarily represent the views of the Latvijas Banka.

Extended author information available on the last page of the article 


\section{Introduction}

In the retail business, exceptional weather is often argued to have an impact on consumer spending. For example, in the UK, the unusually warm Autumn of 2014 was reported to be disastrous for the clothing and footwear stockists. ${ }^{1}$ Such effects of abnormal weather typically manifest themselves as transitory shifts in consumer expenditure. Yet, formal support for this anecdotal evidence has hardly been found as the empirical literature on the impact of (abnormal) weather on consumer spending at aggregate level is still scarce. Obviously, usual weather effects can be easily quantified and removed by standard seasonal adjustment procedures. However, these procedures often struggle to appropriately accommodate the effects of weather anomalies, i.e., (very) untypical weather for a given season or month of the year, and may require non-conventional intervention in order to prevent distortions in the seasonal adjustment of the data of interest. In the light of the continuing dispute on climate change, such weather anomalies are expected to occur more often (Beniston et al. 2007) and to be more extreme (Jakob and Walland 2016; Siliverstovs et al. 2010) than ever witnessed in the past and therefore require a special attention from researchers in order to evaluate their influence on consumer behaviour and eventually on the quality of macroeconomic data.

Compared to the year 1972 when the quote in the first epigraph was made a substantial progress has been made in the marketing science on the interaction of weather conditions and consumer behaviour. Nevertheless, as our second epigraph with the more recently dated quote shows there is still a substantial scope for improving of understanding among economists on how weather deviations from its seasonal norms can influence the economy. It is crucial to determine whether observed changes are of a transitory nature or reflect genuine fundamental shifts in underlying factors. Therefore, impacts caused by exceptional weather are relevant for business cycle analysis and monitoring current economic conditions as well as making projections in the future. Moreover, if abnormal weather affects retail sales, there could also be demand-led effects on inventories, production and employment, to mention but a few. In addition, the knowledge of weather impacts is also crucial for business planning and forecasting, especially for retailers.

Although the influence of extreme weather on consumer behaviour has already been acknowledged in finance, psychology, and marketing literature that relies on the micro-level data such as groups of individuals (Murray et al. 2010), department stores (Linden 1962), or specific products (e.g. cars as in Busse et al. 2015), the literature addressing this question at the macro-level is still limited. The probably first study examining the transitory effects of weather on economic activity is the paper of Maunder (1973). Using weekly non-seasonally adjusted data, his findings indicate that weather conditions can account for a moderate share of the short-term variation in retail trade sales in the US. Also Starr-McCluer (2000) studies the effects of weather on (nominal) retail sales in the US on monthly and quarterly basis. She finds unusual hot and cold weather (measured by cooling and heating days) to have a significant but rather small effect on monthly nominal retail trades. Furthermore, her results reveal

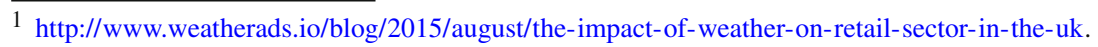


that the effects tend to differ depending on the quarter. (The periodic analysis is done only for quarterly data.)

The main aim of our analysis is to investigate if weather anomalies lead to intertemporal shifts in consumer spending at monthly frequency and to quantify the size of these effects at aggregate level using country-level data for Switzerland. We contribute to the existing literature in different ways. In relation to Maunder (1973) who considers only contemporaneous effects and uses only three years of data, we analyse longer time series and allow also for rebound impacts to get more reliable evidence. Compared to Starr-McCluer (2000), we use more precise weather measures using actual temperature instead of number of cooling or heating days only. More importantly, we conduct the periodic analysis on monthly level to be able to discover the exact nature of abnormal weather effects which tend to "wash out at a quarterly frequency" as noted by StarrMcCluer (2000). Murray et al. (2010), like most of the marketing literature, employ data of a particular store and specific product groups. Nevertheless, for statements of total (nation wide) impacts, aggregate sales data is required. Compared to the USA, Switzerland is a much smaller country and hence more homogeneous with respect to the weather conditions and their deviations from the seasonal norms. This allows us to more accurately capture unusual weather effects at a national level rather than in such a geographically and climatically diverse country as the USA. By analysing national weather indices in such big countries one runs a risk that the estimated impacts of anomalous weather may average out at this level of aggregation. As another contribution to the literature, we follow Boldin and Wright (2015) in quantifying the effects of abnormal weather on consumer spending by constructing counterfactual time series without these effects. We also test whether consumer under-/over-spending due to abnormal weather effects is exactly compensated in the following month, i.e. these effects tend to be short-lived or tend to persist in the long run. Last but not least, besides the listed empirical contributions we suggest a stylised theoretical model allowing for intertemporal shifts in consumer spending due to weather shocks.

Our main findings are following. We find that the intertemporal impacts of weather anomalies on aggregate consumer spending are sizeable. Thus, unusual weather can explain a considerable share of the variability of seasonally adjusted retail sales, especially in the non-food sector. We find that consumers react at most to exceptional temperatures and less to exceptional precipitation or sunshine. This implies that temperature is the most influential weather variable for explaining the intertemporal shifts in consumer spending. Furthermore, the effects of abnormal weather are found to differ across seasons, i.e. to be month-specific, both with respect to sign and magnitude. In particular, our findings indicate that abnormal weather effects manifest mainly during change-of-seasons channel: exceptionally warm temperatures in early spring as well as unusually cold conditions in late summer and early autumn are generally associated with higher sales than usual. That is, abnormal weather conditions in line with the coming season induce consumers to make purchases earlier in the season. When addressing the question whether extraordinary consumption outlays brought about by abnormal weather result in permanent shifts in the level of retail sales, we test and successfully impose restrictions on the estimated model coefficients that rule out such effects in the long run. 
The rest of the paper is structured as follows. The next section discusses the nexus between (abnormal) weather and consumer spending and describes a theoretical model formalising these considerations. Data used in our empirical analysis are described in Sect. 3. Section 4 presents our findings. Robustness of our results is verified in Sect. 6. The final section concludes.

\section{Theoretical considerations}

Already Linden (1962) noted that unusual weather conditions cause shifts in timing of purchases, generate purchases that might otherwise not occur or cause a permanent loss of demand. Yet, the channels of exceptional weather on retail sales are multiple. First, weather may affect consumers' mood and therefore their spending decisions as argued by Murray et al. (2010). The more sunlight, the better is the mood and the higher is the willingness to spend (more) money. We refer to this as mood channel. Second, weather conditions also affect the convenience of the shopping experience (sunny weather vs., heavy rain or snow) and thus, increase or decrease, respectively, the motivation for shopping (convenience channel). Furthermore, weather conditions can boost sales of weather-related products such as air-conditioners, umbrellas and snow shovels (weather-related products). Moreover, when season changes, there is a need for different seasonal products such as apparel or leisure equipment. Unusual bad or good weather can shift sales peaks during the months when new seasonal products are launched (seasons change channel).

To formalize our arguments theoretically, we develop a stylized model of intertemporal consumption. In this model, in line with the discussion earlier, weather conditions directly affect consumption enjoyment, i.e. the utility derived from consumption. Furthermore, we allow the importance of these weather conditions to vary across different seasons. Assuming an isoelastic utility function, this can be formalized as follows:

$$
U_{t}=\frac{C_{t}^{1-\gamma}}{1-\gamma} s_{t}^{\theta_{m}}
$$

where $\gamma$ measures the degree of relative risk aversion, $C$ stands for consumption, $s_{t}$ for the weather state taking value 1 by average (normal) weather, $\theta_{m}$ indexes the importance of the weather state and $m=1, \ldots, 12$ denotes the month in which $t$ falls. $s_{t}$ can be interpreted as a taste-shifter, a variable that shifts marginal utility. We assume life time utility to be additive so that

$$
V_{t}=\sum_{i=0}^{T} \beta^{i} U_{t+i}, \quad 0<\beta \leq 1,
$$

where $\beta$ is a time discount factor. The budget constraint is defined as

$$
C_{t+1}=Y_{t+1}-A_{t+1}+\left(1+r_{t+1}\right) A_{t}
$$


where $Y$ is real income, $r$ is the real interest rate and $A$ is the end-of-period real value assets. Maximization of total utility yields

$$
\frac{C_{t+1}^{-\gamma} s_{t+1}^{\theta_{m+1}}}{C_{t}^{-\gamma} s_{t}^{\theta_{m}}}=\frac{1}{\beta\left(1+r_{t+1}\right)}
$$

Taking logarithms and adding the disturbance give us

$$
\gamma \ln C_{t+1}+\ln s_{t+1}^{\theta_{m+1}}=\gamma \ln C_{t}+\ln s_{t}^{\theta_{m}}-\ln \left(\frac{1}{\beta\left(1+r_{t+1}\right)}+\epsilon_{t+1}\right) .
$$

We assume that the stochastic term is normally and identically distributed

$$
\ln \left(\frac{1}{\beta\left(1+r_{t+1}\right)}+\epsilon_{t+1}\right) \sim N\left(\mu, \sigma^{2}\right)
$$

Thus, we can use the properties of log-normal distributions to derive the following results:

$$
E_{t}\left(\frac{1}{\beta\left(1+r_{t+1}\right)}+\epsilon_{t+1}\right)=\exp \left(\mu+1 / 2 \sigma^{2}\right)
$$

and further,

$$
\mu=\ln \left(1 / \beta\left(1+r_{t+1}\right)\right)-1 / 2 \sigma^{2}
$$

Finally, we can write Eq. (5) as

$$
\ln C_{t+1}=\omega+\frac{\ln \left(1+r_{t+1}\right)}{\gamma}+\ln C_{t}+\theta_{m} \ln s_{t}-\theta_{m+1} \ln s_{t+1}+u_{t+1},
$$

where

$$
\omega_{t}=\frac{1}{\gamma} \ln \left(\beta+1 / 2 \sigma^{2}\right)
$$

Reordering the terms gives us the final specification:

$$
\ln \frac{C_{t+1}}{C_{t}}=\omega+\frac{\ln \left(1+r_{t+1}\right)}{\gamma}+\theta_{m} \ln s_{t}-\theta_{m+1} \ln s_{t+1}+u_{t+1} .
$$

Equation (7) states that the growth in consumption depends on the time discount factor $(\beta)$, the interest rate, the weather state of the current period as well as the weather state of the previous period and the forecast error. This implies that through intertemporal optimization unusual weather may cause shifts in consumption over time. 
Often it is assumed that the utility does not depend only on the current consumption expenditure but also on the previous consumption level. A utility function with habit formation can be written as

$$
U_{t}=\frac{1}{1-\gamma} \tilde{C}_{t}^{1-\gamma} s_{t}^{\theta_{m}}
$$

where $\tilde{C}_{t}=\frac{C_{t}}{C_{t-1}^{\phi}}$ and $\phi$ controls the importance of habit formation. Then, the maximization of total utility yields

$$
\left(\frac{C_{t+1}}{C_{t}^{\phi}}\right)^{-\gamma} \frac{s_{t+1}^{\theta_{m+1}}}{C_{t}^{\phi}}=\left(\frac{C_{t}}{C_{t-1}^{\phi}}\right)^{-\gamma} \frac{s_{t}^{\theta_{m}}}{C_{t-1}^{\phi}} \frac{1}{\beta\left(1+r_{t}\right)}
$$

Under the same assumptions as earlier, we get

$$
\ln \frac{C_{t+1}}{C_{t}}=\omega+\frac{\ln \left(1+r_{t+1}\right)}{\gamma}+\theta_{m} \ln s_{t}+\theta_{m+1} \ln s_{t+1}+\left(1-\frac{1}{\gamma}\right) \phi \ln \frac{C_{t}}{C_{t-1}} .
$$

Now, the growth of consumption depends also on the growth rate of the previous period as well as weather conditions in the current and previous periods.

\section{Data}

For this analysis we employ three data sets: data on weather, retail sales and macroeconomic variables such as interest rates and inflation. The weather data for this paper comes from the Swiss Federal Office of Meteorology and Climatology (MeteoSwiss). The various weather variables are available for numerous weather stations in Switzerland. The national values are defined as simple average of 12 specific weather stations. ${ }^{2}$ Since we want to examine the effects of unusual weather, we construct our weather variables as deviations from the month-specific long-run mean following international standards. ${ }^{3}$ First, we aggregate the data to the national level by averaging monthly observations across the 12 weather stations. Then, the rolling 30-year mean for each month is computed. Finally, we define the deviations as the monthly value minus the (one-year) lagged rolling mean as follows:

$$
W_{t}^{m}=w_{t}^{m}-\frac{1}{30} \sum_{y-31}^{y-1} w_{t, y}^{m}
$$

where $w_{t}^{m}$ denotes the value of the weather variable in month $m$. We repeat this for all the three weather variables we consider: homogenized monthly mean temperature

\footnotetext{
${ }^{2}$ Stations: BAS (Basel), BER (Bern), CHD (Château-d'Oex), CHM (Chaumont), DAV (Davos), ENG (Engelberg), GVE (Geneva-Cointrin), LUG (Lugano), SAE (Saentis), SIA (Segl-Maria), SIO (Sion), SMA (Zurich).

${ }^{3}$ See, Definition of World Meteorological Organization to Climatological Normals: www.wmo.int.
} 


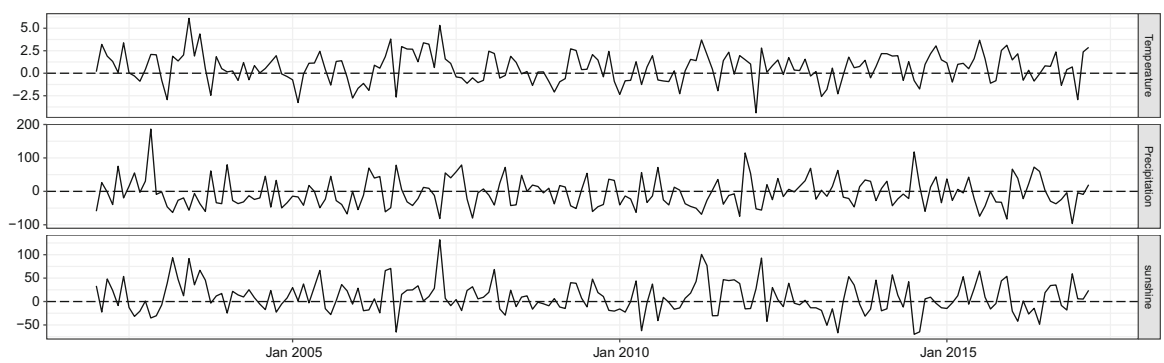

(a) Weather variables - deviations from long-run rolling mean

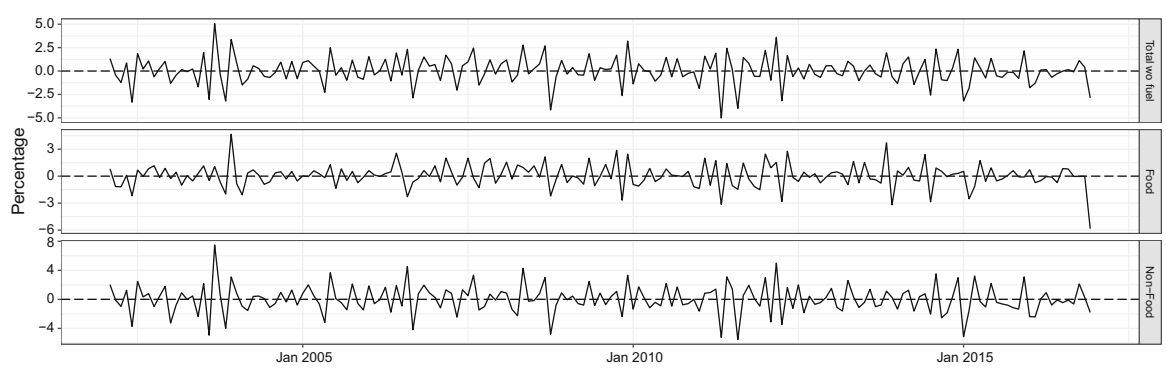

(b) Nominal Retail sales (Month-to-Month growth rates)

Fig. 1 Retail sales and weather variables

( 2 metres above the ground, in degrees Celsius), homogenized monthly mean precipitation (in millimetres) and monthly mean duration of sunshine (in hours). These variables are shown in Fig. 1a. ${ }^{4}$

Since the national accounting data on consumer expenditure for Switzerland is available only at quarterly frequency, we use the retail trade sales to proxy the consumer spending at monthly frequency. The data on retail trade sales turnover in Switzerland is provided by the Swiss Federal Statistical Office (FSO). The indexes start on January 2002. The data are available for total retail trade (NOGA 47) and for the sub-branches. Our main series are the seasonally and calendar effects adjusted retail sector without fuel (NOGA 47 without NOGA 473)[Total wo fuel], retail sales of food, beverages and tobacco (NOGA 4711 and 472) [Food] as well as retail sales of non-food (NOGA 4719, 474-479) [Non-Food]. Figure $1 \mathrm{~b}$ shows the series over the sample period from January 2002 to December 2016. The data on short-term nominal interest rates as well as CPI index were extracted from the SNB Dataportal. In the empirical analysis, we use the following estimation sample 2002M05-2016M12, with four observations lost due to taking first difference of retail sales and using up to three lags of the dependent variable.

\footnotetext{
4 The weather time series is available since 1950. By computing 30-year deviations from average, we lose correspondingly 30 years of data implying that unusual weather time series start in 1980. In Fig. 1a, we show the data since 2002 , i.e. the initial year for which retail sales time series is available.
} 


\section{Empirical analysis}

In this section, we present our estimation results for two model specifications. In Sect. 4.1, we estimate our baseline model where we allow for month-specific or periodic weather effects on retail sales. In Sect. 4.2, we impose additional restrictions on the weather shocks ruling out their permanent effects on the level of retail sales.

\subsection{Initial model with month-specific weather effects}

In this section, we specify our initial model that in line with the rest of the literature lets consumers react differently to weather anomalies at different seasons or months:

$$
\begin{aligned}
\Delta c_{t}=\omega & +\sum_{i=1}^{p} a_{i} \Delta c_{t-i}+\delta R_{t}+\sum_{l=0}^{1} \theta_{1, l} \mathrm{DI}^{\mathrm{Jan}} W_{t-l}+\sum_{l=0}^{1} \theta_{2, l} \mathrm{DI}^{\mathrm{Feb}} W_{t-l}+\cdots \\
& +\sum_{l=0}^{1} \theta_{12, l} \mathrm{DI}^{\mathrm{Dec}} W_{t-l}+\epsilon_{t}
\end{aligned}
$$

where $c_{t}$ denotes $\log$ nominal retail sales (total, food or non-food), $W_{t-l}=$ $\{$ Temp, Rain, Sun $\}$ is one of our weather variables and $\mathrm{DI}^{m}$ an impulse dummy variable taking value 1 in month $m=\{$ Jan, Feb, ldots, Dec $\}$ and zero otherwise. ${ }^{5}$

The results for temperature as weather variable $W_{t}=\{$ Temp $\}$ are presented in Table 1. The first column presents the results for total retail sales as dependent variable, Columns (2) and (3) for food and non-food sales, respectively. Observe that the autoregressive coefficients for lags of the dependent variable are estimated to be strongly negative, implying that there is a rebounce effect in opposite direction in the following month after a positive or negative shock in a specific month. This is consistent with the sawtooth-like pattern in the retail sales growth rates as shown in Fig. 1b. Turning to the estimates of temperature coefficients, one can observe that quite a few of those turn out to be statistically significant; however, with substantial variation both in sign and magnitude. The weather effects are most pronounced for total and non-food retail sales, while to somewhat lesser extent for food retail sales. This observation is supported by the outcome of the test for joint significance of all temperature variables in each of Models (1)-(3). As seen, for total and non-food retail sales, we can decisively reject the null hypothesis that all the temperature variables interacted with monthly dummies can be excluded from the respective models. For food retail sales, the temperature variable exclusion restriction cannot be rejected with the reported $p$ value of 0.46 . Tentatively, this can indicate that for most months of the year food retail sales are less influenced by abnormal weather effects than sales of

\footnotetext{
5 The model in Eq. (12) is a more flexible specification of the following model $\Delta c_{t}=\omega+\sum_{i=1}^{p} a_{i} \Delta c_{t-i}+$ $\delta R_{t}+\sum_{l=0}^{1} \theta_{l} W_{t-l}+\epsilon_{t}$ that imposes a homogeneous reaction of the dependent variable in each month to abnormal weather conditions. It turned out the homogeneity restriction was not supported by the data as abnormal weather effects could not have been detected in this highly restrictive model specification. For the sake of brevity, we did not include these estimation results in the final version but make them available upon request.
} 
Table 1 Month-specific effects of temperature on retail sales

\begin{tabular}{|c|c|c|c|}
\hline & \multicolumn{3}{|l|}{ Dependent variable } \\
\hline & Total & Food & Nonfood \\
\hline & (1) & (2) & (3) \\
\hline Constant & $0.033(0.097)$ & $0.035(0.110)$ & $-0.010(0.123)$ \\
\hline$\Delta c_{t-1}$ & $-0.688^{* * *}(0.077)$ & & \\
\hline$\Delta c_{t-2}$ & $-0.470^{* * *}(0.084)$ & & \\
\hline$\Delta c_{t-3}$ & $-0.164^{* *}(0.071)$ & & \\
\hline$\Delta c_{t-1}$ & & $-0.566^{* * *}(0.089)$ & \\
\hline$\Delta c_{t-2}$ & & $-0.320^{* * *}(0.098)$ & \\
\hline$\Delta c_{t-3}$ & & $-0.137(0.090)$ & \\
\hline$\Delta c_{t-1}$ & & & $-0.626^{* * *}(0.076)$ \\
\hline$\Delta c_{t-2}$ & & & $-0.457^{* * *}(0.078)$ \\
\hline$\Delta c_{t-3}$ & & & $-0.174^{* *}(0.068)$ \\
\hline$R_{t}$ & $0.509^{* * *}(0.115)$ & $0.430^{* * *}(0.127)$ & $0.534^{* * *}(0.144)$ \\
\hline $\mathrm{DI}^{\mathrm{Jan}} \mathrm{Temp}_{t}$ & $0.074(0.187)$ & $0.023(0.216)$ & $0.203(0.236)$ \\
\hline $\mathrm{DI}^{\mathrm{Feb}} \mathrm{Temp}_{t}$ & $0.028(0.140)$ & $-0.123(0.158)$ & $0.211(0.177)$ \\
\hline $\mathrm{DI}^{\mathrm{Mar}} \mathrm{Temp}_{t}$ & $0.503^{* *}(0.199)$ & $0.227(0.226)$ & $0.672^{* * *}(0.254)$ \\
\hline $\mathrm{DI}^{\mathrm{Apr}} \mathrm{Temp}_{t}$ & $0.213(0.139)$ & $0.129(0.157)$ & $0.141(0.177)$ \\
\hline $\mathrm{DI}^{\mathrm{May}} \mathrm{Temp}_{t}$ & $0.068(0.209)$ & $0.055(0.236)$ & $0.052(0.267)$ \\
\hline $\mathrm{DI}^{\mathrm{Jun}} \mathrm{Temp}_{t}$ & $-0.315^{* *}(0.145)$ & $-0.020(0.163)$ & $-0.341^{*}(0.184)$ \\
\hline $\mathrm{DI}^{\mathrm{Jul}} \mathrm{Temp}_{t}$ & $0.197(0.176)$ & $0.454^{* *}(0.199)$ & $0.028(0.222)$ \\
\hline $\mathrm{DI}^{\mathrm{Aug}} \mathrm{Temp}_{t}$ & $-0.615^{* * *}(0.156)$ & $0.126(0.175)$ & $-1.029^{* * *}(0.199)$ \\
\hline $\mathrm{DI}^{\mathrm{Sep}} \mathrm{Temp}_{t}$ & $-0.327^{*}(0.182)$ & $-0.112(0.206)$ & $-0.543^{* *}(0.231)$ \\
\hline $\mathrm{DI}^{\mathrm{Oct}} \mathrm{Temp}_{t}$ & $-0.697^{* * *}(0.214)$ & $-0.337(0.235)$ & $-0.884^{* * *}(0.276)$ \\
\hline $\mathrm{DI}^{\mathrm{Nov}} \mathrm{Temp}_{t}$ & $-0.241(0.162)$ & $-0.242(0.182)$ & $-0.299(0.205)$ \\
\hline $\mathrm{DI}^{\mathrm{Dec}} \mathrm{Temp}_{t}$ & $0.195(0.210)$ & $-0.132(0.237)$ & $0.295(0.265)$ \\
\hline $\mathrm{DI}^{\mathrm{Jan}} \mathrm{Temp}_{t-1}$ & $0.114(0.202)$ & $0.397^{*}(0.225)$ & $-0.141(0.258)$ \\
\hline $\mathrm{DI}^{\mathrm{Feb}} \mathrm{Temp}_{t-1}$ & $-0.152(0.192)$ & $0.216(0.220)$ & $-0.431^{*}(0.244)$ \\
\hline $\mathrm{DI}^{\mathrm{Mar}} \mathrm{Temp}_{t-1}$ & $-0.160(0.119)$ & $-0.022(0.134)$ & $-0.221(0.151)$ \\
\hline $\mathrm{DI}^{\mathrm{Apr}} \mathrm{Temp}_{t-1}$ & $-0.093(0.206)$ & $-0.028(0.230)$ & $-0.159(0.263)$ \\
\hline $\mathrm{DI}^{\mathrm{May}} \mathrm{Temp}_{t-1}$ & $-0.374^{* *}(0.153)$ & $-0.213(0.172)$ & $-0.414^{* *}(0.194)$ \\
\hline $\mathrm{DI}^{\mathrm{Jun}} \mathrm{Temp}_{t-1}$ & $0.187(0.207)$ & $0.076(0.233)$ & $0.259(0.264)$ \\
\hline $\mathrm{DI}^{\mathrm{Jul}} \mathrm{Temp}_{t-1}$ & $-0.049(0.146)$ & $-0.118(0.160)$ & $0.111(0.184)$ \\
\hline $\mathrm{DI}^{\text {Aug }} \mathrm{Temp}_{t-1}$ & $0.271^{*}(0.157)$ & $0.026(0.180)$ & $0.401^{* *}(0.200)$ \\
\hline $\mathrm{DI}^{\mathrm{Sep}} \mathrm{Temp}_{t-1}$ & $0.461^{* * *}(0.163)$ & $0.283(0.175)$ & $0.567^{* * *}(0.213)$ \\
\hline $\mathrm{DI}^{\mathrm{Oct}} \mathrm{Temp}_{t-1}$ & $0.416^{* *}(0.198)$ & $0.093(0.221)$ & $0.664^{* * *}(0.253)$ \\
\hline $\mathrm{DI}^{\mathrm{Nov}} \mathrm{Temp}_{t-1}$ & $0.157(0.202)$ & $0.251(0.219)$ & $0.173(0.260)$ \\
\hline $\mathrm{DI}^{\mathrm{Dec}} \mathrm{Temp}_{t-1}$ & $0.399^{* *}(0.196)$ & $0.252(0.220)$ & $0.485^{*}(0.246)$ \\
\hline BP-test ( $p$ value) & 0.61 & 0.72 & 0.68 \\
\hline LH test ( $p$ value) & 0.00 & 0.46 & 0.00 \\
\hline
\end{tabular}


Table 1 continued

\begin{tabular}{llll}
\hline & \multicolumn{2}{l}{ Dependent variable } & \\
\cline { 2 - 4 } & Total & Food & Nonfood \\
\cline { 2 - 4 } & $(1)$ & $(2)$ & $(3)$ \\
\hline Observations & 176 & 176 & 176 \\
$R^{2}$ & 0.608 & 0.330 & 0.633 \\
Adjusted $R^{2}$ & 0.534 & 0.202 & 0.564 \\
\hline
\end{tabular}

${ }^{*} p<0.1 ;{ }^{* *} p<0.05 ;{ }^{* * *} p<0.01$

S.E. are reported in parentheses. $\mathrm{BP}=\mathrm{Box}-$ Pierce test of no residual autocorrelation, $\mathrm{LH}=$ Linear Hypothesis test of joint exclusion restrictions of weather-related variables. Dependent variable $\left(\Delta c_{t}\right)$ is nominal retail trade turnover in log differences (in percentage). $\Delta c_{t-i}$ denote the lagged dependent variables, $R_{t}=$ $\ln \left(1+r_{t}\right)$, whereas $r_{t}$ is the short-term interest rate, Temp $\mathrm{p}_{t}$ is the temperature variable, $\mathrm{DI}^{m}$ is an impulse dummy variable that takes value of 1 in month $m$ and zero otherwise

non-food products. We verify the conclusion of the joint significance of the temperature variables for all kinds of the dependent variable again using a more parsimonious model specification reported in the next section. The outcome of the test for joint significance of the temperature variables is also consistent with the reported measure of goodness-of-fit adjusted- $R^{2}$ for each model in Table 1 . Both for total and non-food retail sales the adjusted- $R^{2}$ is estimated 0.534 and 0.564 , respectively, which substantially larger than the value of 0.333 observed for food retail sales. Finally, we also report the outcome of the Box-Pierce test of the null hypothesis of no residual serial autocorrelation. As seen, we cannot reject the null hypothesis of the Box-Pierce test at the usual significance levels.

Upon examining the pattern of abnormal weather shocks on retail sales, we find those are straightforward to rationalise. For example, the estimate for March is found to be positive indicating that unusual warm weather in March induces consumers sooner than usual to change their consumption pattern adapted during the winter thus boosting the retail sales. The coefficient on June temperature is, in turn, found to be negative implying that abnormal hot weather during the summer month exercises a dampening effect on the retail sales. From August to October, the coefficients on the temperature dummies are negative and significant, with the October coefficient having the highest value. This finding implies that abnormal warm weather conditions during early autumn have negative impact on the retail sales hindering changes in the wardrobe and shifting the seasonal sales peaks later. ${ }^{6}$

A further insight into seasonal variation in reaction of retail sales to abnormal weather pattern can be gained from Fig. 2 where the estimated coefficients for

\footnotetext{
6 We complement the results reported in the main text by extensive robustness checks relegated to Appendix. For example, we estimate models with precipitation and sunshine as weather variables. These additional results are qualitatively in line with those from the model with temperature: abnormal nice weather (less rain or more sunshine, respectively) in spring months boost the sales of retailers, whereas it inhibits consumer spending in early autumn. Though, there is not much of a strong statistical evidence supporting this finding as hardly any of the coefficients for rain and sunshine variables are significant. In addition to this, a number of alternative model specifications using the temperature variable is reported in Appendix. There we verify robustness of our main results using sparse model specification, alternative estimation techniques (quantile regressions), different definitions of dependent variable, and several alternative explanatory variables.
} 

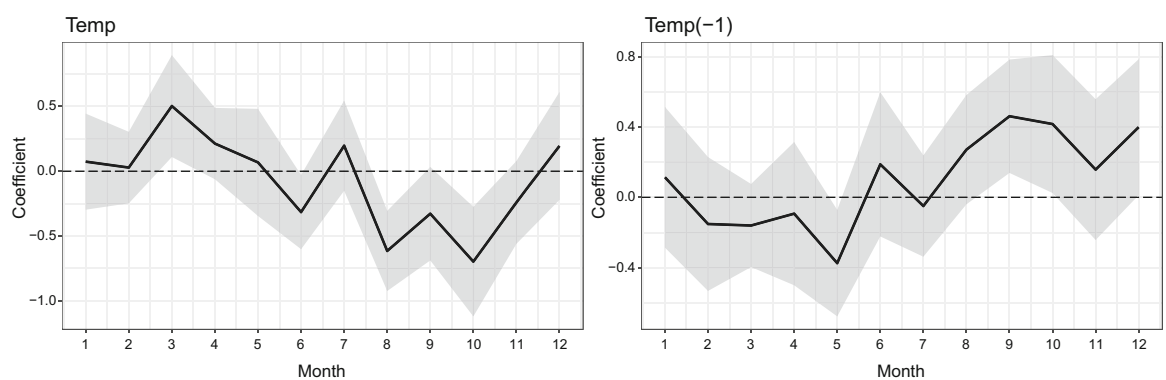

Fig. 2 Month-specific coefficients of temperature variables (model (1) in Table 1). The shaded region indicates $95 \%$ confidence intervals for estimated coefficients

temperature variables in the regression for total retail sales (Model (1) in Table 1) are shown along with $95 \%$ confidence intervals. It is worthwhile noticing that for contemporaneous temperature effects estimated coefficients are positive in the first half of the year and turning negative in the second half of the year. For the lagged temperature effects, we obtain a mirroring image. That is the temperature effects are generally negative in the first half of the year turning positive in the second half of the year. This pattern is consistent with the observation made earlier that shifts in consumer behaviour induced by unusual weather are rather of a transitory nature and quickly tend to be compensated in the following months. In the next section, we will adopt the approach of Boldin and Wright (2015) formally test the hypothesis whether the effect of abnormal weather shocks eventually dies out, i.e. there is no permanent effect on the future level of retail sales. That is we will test the restriction whether extraordinary outlays or savings induced by unusual weather in the current month tend to be exactly compensated in the following months.

Our results allow us to draw several conclusions regarding the relative importance of different channels through which abnormal weather is expected to affect consumer spending decisions. First, our findings do not support the mood channel since unusually good weather (warm, sunny, less rain) is found to have in some months positive and other months negative effects, if the mood effect would be the main channel, we would expect the coefficients be always positive. Also the convenience channel does not find great support for similar reasons, bad weather seems to boost the sales in specific months. The weather-related products do not seem to play crucial role either since the impacts in winter or summer months are quantitatively small and not significant, except one. Yet, we find strong support for the seasons change channel. Abnormal high temperatures foster seasonal product sales in spring, i.e. make new seasonal products more appealing. On the other hand, especially cold weather conditions lead to higher sales in late summer and early autumn. That is, weather conditions in line with the coming season induce consumers to make the purchases earlier than usual in the season. This implies that depending on a time of the year both unusually hot or cold weather can positively affect retail sales and other way around. 


\subsection{Restricted model with month-specific weather effects}

In the previous section, we documented the presence of a rebound effect of the abnormal weather (in the following months) on retail sales. In the unrestricted version of the model in Eq. (12), weather shocks though mitigated in the following month are still allowed to have a permanent effect on the level of retail sales. However, consistent with the idea of a temporary nature of weather shocks it is of a further interest to test whether these permanent effects on the level of retail sales can be ruled out. In doing so, we follow Boldin and Wright (2015) (BW) and define monthly (dummy) variables such that they take 1 in a specific month (to capture the current weather effect) and -1 in the following month, i.e. the weather effect of an equal size but opposite sign is imposed for the following month, and 0 otherwise. As argued in Boldwin and Wright (2015, p. 254), such model specification given the presence of lagged dependent variable eventually imposes the long-run neutrality of the weather shocks at the level of retail sales. ${ }^{7}$

The resulting model is specified as follows:

$$
\begin{aligned}
\Delta C_{t}= & \omega+\sum_{i=1}^{p} a_{i} \Delta C_{t-i}+\delta R_{t}+\theta_{1} \mathrm{DTI}^{\mathrm{Jan}} W_{t}+\theta_{2} \mathrm{DTI}^{\mathrm{Feb}} W_{t} \\
& +\cdots+\theta_{12} \mathrm{DTI}^{\mathrm{Dec}} W_{t}+\epsilon_{t},
\end{aligned}
$$

where $\mathrm{DTI}^{m}$ are the transitory impulse dummy defined in the previous paragraph.

The estimation results of Eq. (13) for total retail sales, food and non-food sector are shown in Table 2. The likelihood-ratio (LR) test indicates that we cannot reject these BW restrictions against the previous (unrestricted) specification reported in Table 1 in Sect. 4.1. Hence, our results are in line with those of Boldin and Wright (2015) where they also find that long-run neutrality of abnormal weather shocks is generally supported by the data representing several main categories of the macroeconomic variables.

The estimation results reported in Column (1) of Table 2 are similar to the results reported above for the unrestricted version of the model. Here, also we find a positive effect of excess temperatures in the early spring months, adverse effect in June and from August to November. In the other two columns, we document the results for food and non-food sectors separately. The findings suggest that weather affects mainly the non-food sales, with food sales affected by abnormal weather to a lesser extent and mostly only in months of the last quarter of the year. We also report the outcome of the test of the joint exclusion restrictions $(\mathrm{LH})$ of the weather-related variables, i.e. $H_{0}: \theta_{1}=\theta_{2}=\cdots=\theta_{12}=0$ in Eq. (13); for total and non-food retail sales, we can reject the null hypothesis, whereas for food retail sale, we cannot reject the respective null hypothesis. This can be explained by the fact that in Model (2), only three out of twelve temperature-related coefficients are statistically significant at the usual significance levels.

\footnotetext{
7 For more information on the dynamic effects of the intervention dummies in models involving stationary transformations of I(1) variables, see Hendry and Juselius (2001, p. 104).
} 
Table 2 Month-specific effects of temperature with long-run restriction

\begin{tabular}{|c|c|c|c|}
\hline & \multicolumn{3}{|l|}{ Dependent variable } \\
\hline & $\begin{array}{l}\text { Total } \\
\text { (1) }\end{array}$ & $\begin{array}{l}\text { Food } \\
\text { (2) }\end{array}$ & $\begin{array}{l}\text { Non-food } \\
\text { (3) }\end{array}$ \\
\hline Constant & $0.035(0.080)$ & $0.079(0.089)$ & $-0.024(0.102)$ \\
\hline$\Delta c_{t-1}$ & $-0.602^{* * *}(0.069)$ & & \\
\hline$\Delta c_{t-2}$ & $-0.404^{* * *}(0.078)$ & & \\
\hline$\Delta c_{t-3}$ & $-0.123^{*}(0.068)$ & & \\
\hline$\Delta c_{t-1}$ & & $-0.503^{* * *}(0.082)$ & \\
\hline$\Delta c_{t-2}$ & & $-0.263^{* * *}(0.090)$ & \\
\hline$\Delta c_{t-3}$ & & $-0.095(0.084)$ & \\
\hline$\Delta c_{t-1}$ & & & $-0.567^{* * *}(0.068)$ \\
\hline$\Delta c_{t-2}$ & & & $-0.434^{* * *}(0.074)$ \\
\hline$\Delta c_{t-3}$ & & & $-0.161^{* *}(0.066)$ \\
\hline$R_{t}$ & $0.390^{* * *}(0.104)$ & $0.330^{* * *}(0.113)$ & $0.454^{* * *}(0.131)$ \\
\hline $\mathrm{DTI}^{\mathrm{Jan}} \mathrm{Temp}_{t}$ & $0.181(0.124)$ & $-0.027(0.143)$ & $0.346^{* *}(0.156)$ \\
\hline $\mathrm{DTI}^{\mathrm{Feb}} \mathrm{Temp}_{t}$ & $0.105(0.088)$ & $-0.018(0.098)$ & $0.211^{*}(0.111)$ \\
\hline $\mathrm{DTI}^{\mathrm{Mar}^{2}} \mathrm{Temp}_{t}$ & $0.353^{* *}(0.143)$ & $0.152(0.158)$ & $0.476^{* * *}(0.182)$ \\
\hline $\mathrm{DTI}^{\mathrm{Apr}} \mathrm{Temp}_{t}$ & $0.301^{* * *}(0.097)$ & $0.170(0.106)$ & $0.272^{* *}(0.122)$ \\
\hline DTI $^{\text {May }}$ Temp $_{t}$ & $-0.045(0.137)$ & $-0.022(0.152)$ & $-0.122(0.174)$ \\
\hline $\mathrm{DTI}^{\mathrm{Jun}} \mathrm{Temp}_{t}$ & $-0.167^{*}(0.094)$ & $0.014(0.103)$ & $-0.252^{* *}(0.119)$ \\
\hline $\mathrm{DTI}^{\mathrm{Jul}} \mathrm{Temp}_{t}$ & $-0.094(0.113)$ & $0.180(0.125)$ & $-0.218(0.143)$ \\
\hline DTI $^{\text {Aug }} \mathrm{Temp}_{t}$ & $-0.563^{* * *}(0.114)$ & $-0.068(0.121)$ & $-0.833^{* * *}(0.147)$ \\
\hline $\mathrm{DTI}^{\mathrm{Sep}} \mathrm{Temp}_{t}$ & $-0.337^{* *}(0.131)$ & $-0.101(0.144)$ & $-0.549^{* * *}(0.166)$ \\
\hline $\mathrm{DTI}^{\mathrm{Oct}} \mathrm{Temp}_{t}$ & $-0.423^{* * *}(0.143)$ & $-0.296^{*}(0.151)$ & $-0.503^{* * *}(0.186)$ \\
\hline $\mathrm{DTI}^{\mathrm{Nov}} \mathrm{Temp}_{t}$ & $-0.375^{* * *}(0.116)$ & $-0.301^{* *}(0.129)$ & $-0.419^{* * *}(0.145)$ \\
\hline $\mathrm{DTI}^{\mathrm{Dec}} \mathrm{Temp}_{t}$ & $0.093(0.131)$ & $-0.292^{* *}(0.145)$ & $0.293^{*}(0.167)$ \\
\hline LR-test ( $p$ value) & 0.229 & 0.693 & 0.304 \\
\hline BP-test ( $p$ value) & 0.58 & 0.82 & 0.57 \\
\hline LH-test ( $p$ value) & 0.00 & 0.17 & 0.00 \\
\hline Observations & 176 & 176 & 176 \\
\hline$R^{2}$ & 0.573 & 0.294 & 0.603 \\
\hline Adjusted $R^{2}$ & 0.530 & 0.223 & 0.563 \\
\hline
\end{tabular}

${ }^{*} p<0.1 ;{ }^{* *} p<0.05 ;{ }^{* * *} p<0.01$

S.E. are reported in parentheses. LR $=$ Likelihood-ratio test of long-run neutrality of abnormal weather shocks (Boldin and Wright 2015), BP = Box-Pierce test of no residual autocorrelation, $\mathrm{LH}=\mathrm{Linear}$ Hypothesis test of joint exclusion restrictions of weather-related variables. Dependent variable $\left(\Delta c_{t}\right)$ is nominal retail trade turnover in log differences (in percentage points). $\Delta c_{t-i}$ denote the lagged dependent variables, $R_{t}=\ln \left(1+r_{t}\right)$, whereas $r_{t}$ is the short-term interest rate, Temp $\mathrm{p}_{t}$ is the temperature variable, $\mathrm{DTI}^{m}$ is a transitional impulse dummy variable taking 1 in month $m$ and -1 in the following month and zero otherwise 
Table 3 Measuring explanatory power of weather variables: incremental adjusted $R^{2}$

\begin{tabular}{lcrc}
\hline & Total & Food & Non-food \\
\hline Temperature & 0.16 & 0.02 & 0.17 \\
Precipitation & 0.03 & -0.00 & 0.02 \\
Sunshine & 0.06 & 0.07 & -0.19 \\
\hline
\end{tabular}

Differences in adjusted $R^{2}$ between models with and without weather variables are reported for regressions presented in Table 3
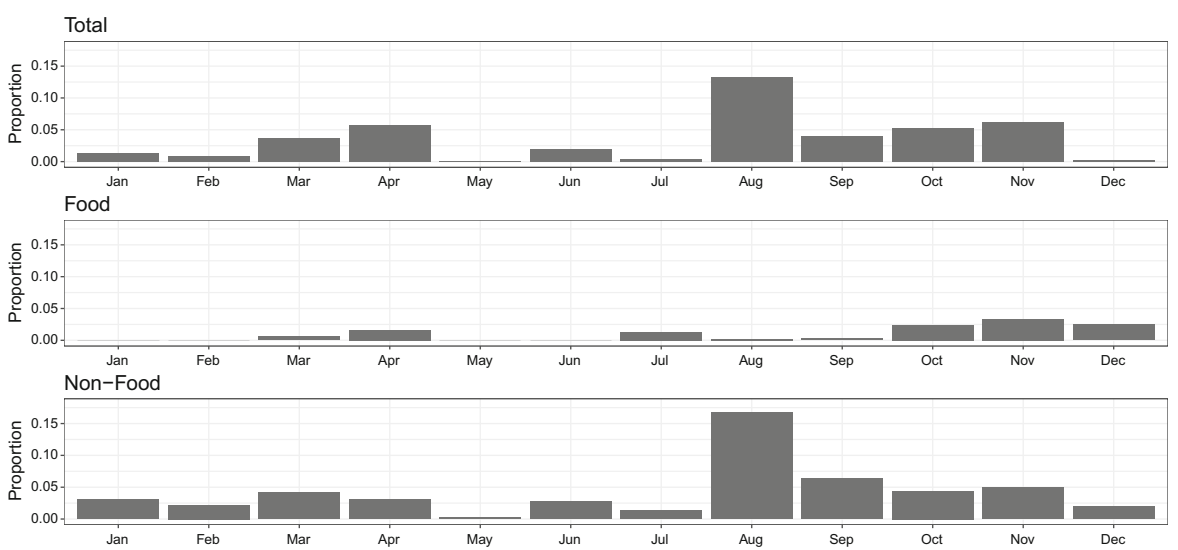

Fig. 3 Partial $R^{2}$ Note Upper, middle, and lower panels correspond to estimation results reported for models (1), (2), and (3), respectively, in Table 2

\subsection{Gauging the significance of weather effects}

In this subsection, we address the significance of weather effects both from statistical and quantitative points of view. In doing so, we complement the results reported above on significance testing of the weather-related coefficients in the empirical models.

First, we can evaluate magnitude of the change in adjusted $R^{2}$ for model without and with weather variables that measures the extent of additional explanatory power of the weather variables for the variation in retail sales controlling for the number of estimated parameters. These results are reported in Table 3 for different categories of retail sales and all three types of weather variables $W=\{$ Temp, Rain, Sun $\}$ of interest. Consistent with the results reported above in Tables 1 and 2, we find the largest contribution for extreme temperatures especially for total and non-food retail sales. Inclusion of the temperature variable in the model for these two variables boosts the regression explanatory power by 16 and 17 sales are affected to a much lesser extent by all of the weather variables, whereas inclusion of sunshine hours in the models for non-food sales substantially worsens (adjusted) $R^{2}$.

Second, we can assess the quantitative implications of these abnormal weather effects separately for each month. To this end, we calculate the partial $R^{2}$ for each of the month-specific weather variable in order to single out those months that contribute the most to explaining variation in consumer spending in response to the weather deviations from its seasonal norms. The bars in Fig. 3 tells us the proportion of variation 
explained by each month that cannot be explained by the other variables. The highest value is found for August indicating that the temperature in August can explain around $13 \%$ of the variation in the total retail sales, for non-food even more than $15 \%$ cannot be captured by the other variables.

Last but not least, an additional way to quantify the weather impact is to define a counterfactual series as in Boldin and Wright (2015). The counterfactual series describe how retail sales would have evolved if there would have not been any unusual weather effects, that is, the weather effect is subtracted out. This is done by calculating fitted values in Eq. (13) without weather effects by setting the weather-related coefficients to zero. Then, the sum of these newly calculated fitted values and the original residuals are the counterfactual series. The difference between the original series (that include naturally the abnormal weather effects as well as all other effects) and the counterfactual series can then be interpreted as the size of the unusual weather effect (in percentage points) for each time point. For example, in the officially published total retail sales, the monthly growth rate in March and April 2016 was 0.11 and $0.16 \%$ points, respectively, i.e. we observe small but positive growth in these months. However, after adjusting for the unusual weather effects, one obtains much stronger positive growth of $0.61 \%$ points in March and negative growth of $0.22 \%$ points in April 2016.

An summary of month-specific unusual weather effects (the difference between original and counterfactual time series) is shown in Fig. 4. Observe that the highest median absolute weather effects are found in August, September and November of size around $0.6-0.7 \%$ points indicating that temperature anomalies can account for a noticeable change in the retail sales growth. The biggest (absolute) contribution of unusual temperature in September is as high as $2.5 \%$ points. For almost half of the months the median absolute temperature effect is over $0.5 \%$ points. As before, our results suggest that the non-food sector is influenced much more strongly by exceptional temperatures than the food retail sales. For the non-food sector, the highest median effect of slightly more than $1 \%$ point is found for August and the highest impact of almost $4 \%$ points on non-food retail sales is recorded in September.

One can further compare these effects of abnormal temperatures on total retail sales with month-specific absolute values of the monthly growth rate of this variable, see Table 4. From this table, we can infer that absolute monthly growth rates vary in the interval between 0.85 and $1.41 \%$ points. These values combined with those reported in Fig. 4 imply that abnormal temperature effects do exert a substantial influence on the monthly growth rates of retail sales. Thus our findings conform with those reported in Boldin and Wright (2015) that seasonal effects of abnormal weather shocks on macroeconomic data are enormous and in order to better capture the underlying momentum of the economy these effects need also to be taken into consideration to a similar degree as regular seasonal and calendar patterns are usually taken.

\section{Conclusions}

Already Linden (1962) noted that unusual weather conditions cause shifts in timing of purchases, generate purchases that might otherwise not occur or cause a permanent 
Table 4 Average monthly growth rates of nominal total retail sales (in percent)

\begin{tabular}{lrlllllllllll}
\hline & Jan & \multicolumn{1}{l}{ Feb } & \multicolumn{2}{l}{ Mar Apr } & \multicolumn{1}{l}{ May } & Jun & Jul & Aug & Sep & Oct & Nov & Dec \\
\hline Mean & -0.26 & -0.04 & 0.40 & -0.05 & -0.32 & 0.05 & 0.18 & 0.01 & 0.45 & -0.27 & -0.18 & 0.54 \\
Mean (absolute) & 1.34 & 0.99 & 0.85 & 0.86 & 1.41 & 1.28 & 0.80 & 1.25 & 1.35 & 0.93 & 1.07 & 1.36 \\
\hline
\end{tabular}
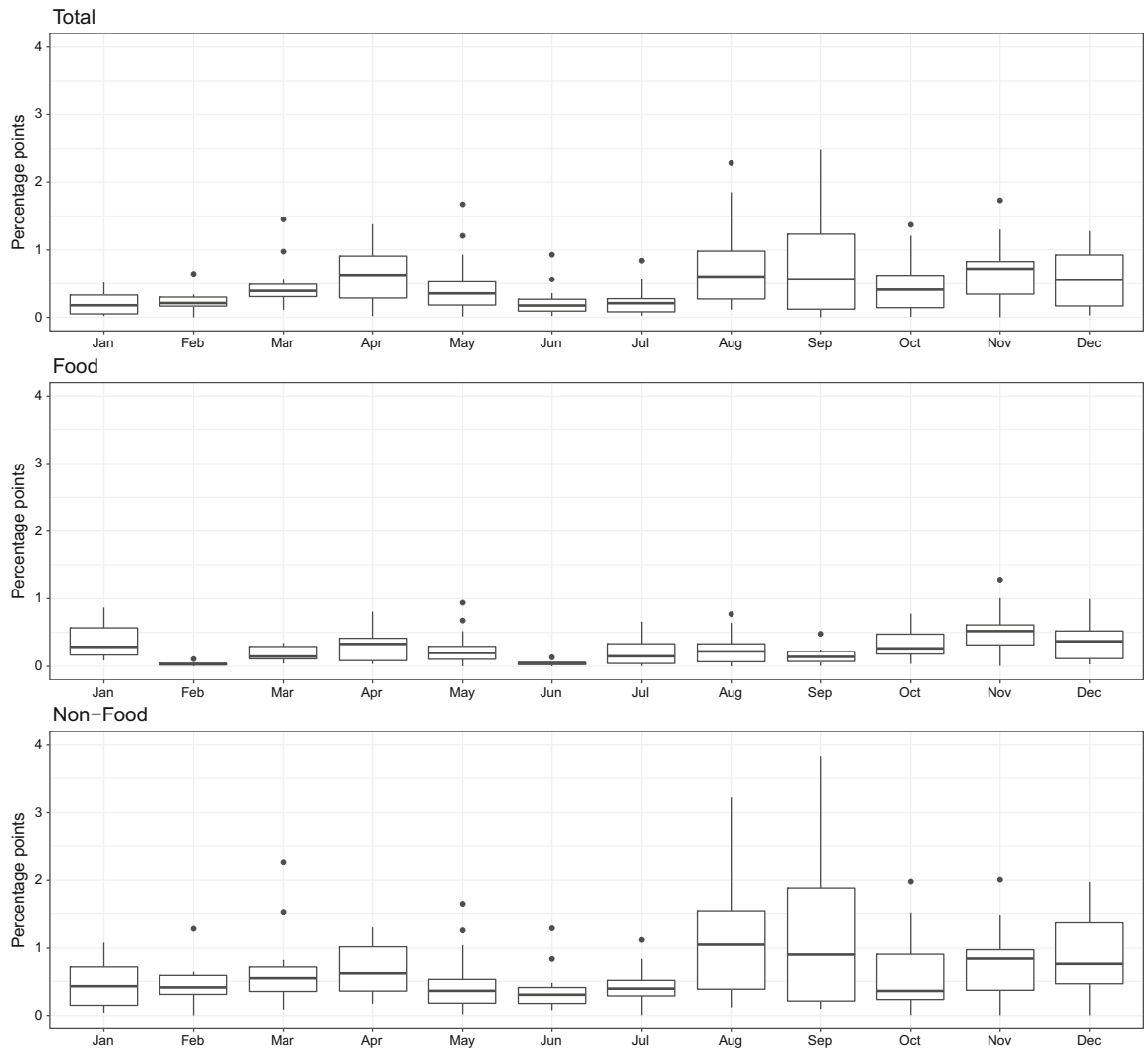

Fig. 4 Counterfactual analysis: absolute month-specific temperature effects. Note Upper, middle, and lower panels correspond to estimation results reported for models (1), (2), and (3), respectively, in Table 2

loss of demand. Also in the business press, exceptional weather is often argued to have an impact on consumer spending and business activity in general, being one of the main causes for the transitory shifts. Yet, the formal evidence for the impact of weather anomalies on consumer expenditure at the macro-level is still limited.

In this paper, we contribute to the so far scarce literature by examining the influence of unusual weather conditions on consumer spending at aggregate level using countrylevel data for Switzerland. We develop a theoretical model based on consumer choice to illustrate how abnormal weather can affect the utility. Based on these theoretical considerations, we conduct a comprehensive periodic analysis. 
Our empirical findings reveal that weather anomalies do cause substantial intertemporal shifts in consumer expenditure, measured by monthly retail sales, at aggregate level in Switzerland. Thus, they can explain a considerable share of the variability of seasonally adjusted retail sales, especially in the non-food sector. We find that consumers react at most to exceptional temperatures, less to abnormal precipitation or sunshine, implying that temperature is the most influential weather variable for explaining volatility of retail sales. Furthermore, the effects of abnormal weather are found to differ across seasons, i.e. to be month-specific, both in sign and magnitude. In particular, our findings indicate that weather effects manifest mainly through the seasons change channel: exceptionally warm weather in spring tends to boost the sales (good to be good), whereas unusually cold conditions in late summer/early autumn are generally associated with higher sales (good to be bad). That is, weather conditions in line with the coming season induce consumers to make their purchases early in the season. In other words, depending on the season (or month) unusually good or bad weather may boost or delay consumer expenditures compared to periods with seasonally normal weather.

An interesting extension of our study is to investigate whether there is certain nonlinearity in consumer reaction to abnormal weather effect, for example, reaction of retail sales to very extreme deviations of the weather variables, e.g. resulting in shutting down of businesses and shopping centres, is likely to be different from situations when these shopping outlets continue to work in the presence of mild abnormal seasonal effects. A proper way to detect such nonlinearities in the data at hand would be to estimate threshold effects either by a standard threshold-type econometric models or by resorting to the methods provided by the modern machine learning literature, e.g. random forests, see the classical contribution of Breiman (2001) or one of the more recent ones (Goulet Coloumbe 2020).

Funding Open Access funding enabled and organized by Projekt DEAL.

\section{Compliance with ethical standards}

Conflict of interest Author A declares that he/she has no conflict of interest. Author B declares that he/she has no conflict of interest.

Ethical approval This article does not contain any studies with human participants or animals performed by any of the authors.

Open Access This article is licensed under a Creative Commons Attribution 4.0 International License, which permits use, sharing, adaptation, distribution and reproduction in any medium or format, as long as you give appropriate credit to the original author(s) and the source, provide a link to the Creative Commons licence, and indicate if changes were made. The images or other third party material in this article are included in the article's Creative Commons licence, unless indicated otherwise in a credit line to the material. If material is not included in the article's Creative Commons licence and your intended use is not permitted by statutory regulation or exceeds the permitted use, you will need to obtain permission directly from the copyright holder. To view a copy of this licence, visit http://creativecommons.org/licenses/by/4.0/. 


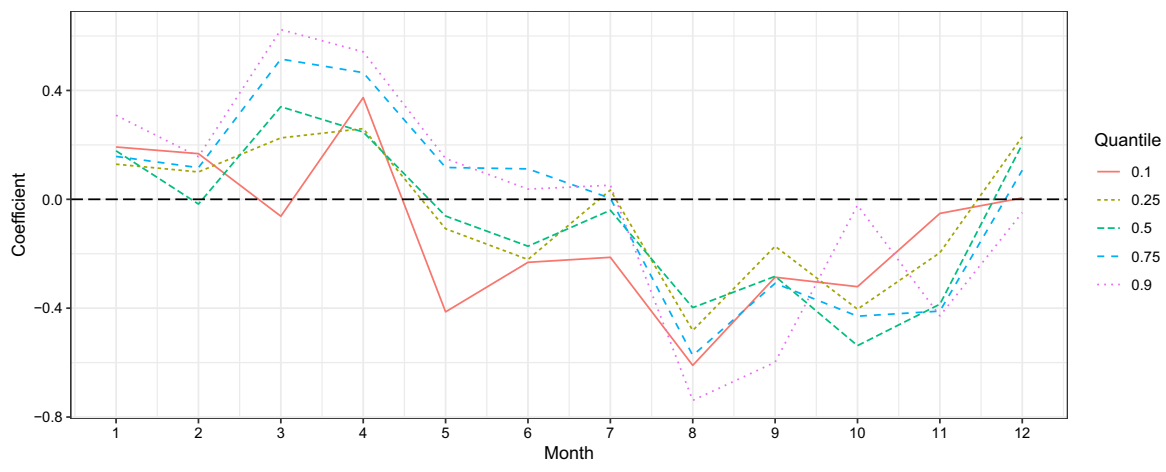

Fig. 5 Month-specific coefficients of temperature variable for the different quantiles of the dependent variable

\section{Appendix: Robustness}

In order to verify the robustness of our results reported in the main text, we estimated a number of alternative model specifications addressing the problem of over-fitting, possible tail effects, definitions of dependent variable and different choices of weather and other explanatory variables.

The estimation results of Eq.(12) using rain and sunshine weather variables are reported in Tables 5 and 6.

From Table 1 in the main text, one can infer that the number of estimated parameters is rather high compared to the number of observations, pointing out to the potential problem of overfitting. In order to address this issue, we applied the variable selection procedure based on the LASSO (Least Absolute Shrinkage and Selection Operator) regression. The LASSO regression retains most relevant variables in the model while removing those with much less explanatory power. In Table 7, we report the results of the re-estimated model with fewer variables as suggested by LASSO procedure. As seen, the main findings reported for the larger model still remain the same.

To examine if these weather effects differ in tails, that is if very high or low retail sales growth is affected more by the unusual weather than median retail sales growth, we employ quantile regressions. We estimate the regressions for the $0.1,0.25,0.5,0.75$ and 0.9 quantiles. In Fig. 5, the estimated coefficients for the weather variables over the months are plotted. All in all, a very similar pattern of OLS-estimated monthly coefficients presented in Fig. 2 can be observed from quantile regression estimation results, with a few exceptions, e.g. the estimate of March coefficient for first decile quantile regression turns out very close to zero and negative, whereas for all other quantiles and OLS regressions in the main text its estimates are positive.

To examine if our results are sensitive to the definition of the dependent variable, we estimate also the main equations using real retail sales instead of nominal as well as year-to-year growth rates instead of month-to-month specification. Table 8 provides the results for the specification in real terms. The outcomes are very much like those in Table 2. We again found the expected negative sign for the real short-term interest rates. 
Table 5 Month-specific effects of rain

\begin{tabular}{|c|c|c|c|}
\hline & \multicolumn{3}{|l|}{$\underline{\text { Dependent variable }}$} \\
\hline & $\begin{array}{l}\text { Total } \\
\text { (1) }\end{array}$ & $\begin{array}{l}\text { Food } \\
\text { (2) }\end{array}$ & $\begin{array}{l}\text { Nonfood } \\
\text { (3) }\end{array}$ \\
\hline Constant & $-0.023(0.100)$ & $0.049(0.099)$ & $-0.087(0.130)$ \\
\hline$\Delta c_{t-1}$ & $-0.750^{* * *}(0.080)$ & & \\
\hline$\Delta c_{t-2}$ & $-0.472^{* * *}(0.088)$ & & \\
\hline$\Delta c_{t-3}$ & $-0.188^{* *}(0.077)$ & & \\
\hline$\Delta c_{t-1}$ & & $-0.566^{* * *}(0.088)$ & \\
\hline$\Delta c_{t-2}$ & & $-0.298^{* * *}(0.095)$ & \\
\hline$\Delta c_{t-3}$ & & $-0.112(0.085)$ & \\
\hline$\Delta c_{t-1}$ & & & $-0.751^{* * *}(0.078)$ \\
\hline$\Delta c_{t-2}$ & & & $-0.537^{* * *}(0.085)$ \\
\hline$\Delta c_{t-3}$ & & & $-0.262^{* * *}(0.075)$ \\
\hline$R_{t}$ & $0.409^{* * *}(0.130)$ & $0.398^{* * *}(0.127)$ & $0.445^{* * *}(0.168)$ \\
\hline $\mathrm{DI}^{\mathrm{Jan}} \operatorname{Rain}_{t}$ & $0.014 *(0.008)$ & $0.017^{* *}(0.008)$ & $0.013(0.011)$ \\
\hline $\mathrm{DI}^{\mathrm{Feb}} \mathrm{Rain}_{t}$ & $-0.003(0.010)$ & $-0.006(0.010)$ & $0.006(0.013)$ \\
\hline 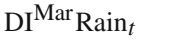 & $-0.012(0.009)$ & $-0.006(0.008)$ & $-0.011(0.011)$ \\
\hline $\mathrm{DI}^{\mathrm{Apr}} \operatorname{Rain}_{t}$ & $-0.009(0.008)$ & $-0.005(0.008)$ & $-0.010(0.010)$ \\
\hline DI $^{\text {May }} \operatorname{Rain}_{t}$ & $-0.003(0.007)$ & $-0.002(0.007)$ & $-0.002(0.009)$ \\
\hline $\mathrm{DI}^{\mathrm{Jun}} \operatorname{Rain}_{t}$ & $-0.002(0.008)$ & $-0.011(0.008)$ & $0.001(0.011)$ \\
\hline $\mathrm{DI}^{\mathrm{Jul}} \operatorname{Rain}_{t}$ & $-0.007(0.007)$ & $-0.008(0.006)$ & $-0.004(0.009)$ \\
\hline $\mathrm{DI}^{\text {Aug }}$ Rain $_{t}$ & $0.015^{* *}(0.006)$ & $-0.005(0.006)$ & $0.024^{* * *}(0.008)$ \\
\hline 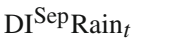 & $-0.014(0.010)$ & -0.007 (0.009) & $-0.012(0.013)$ \\
\hline $\mathrm{DI}^{\mathrm{Oct}} \operatorname{Rain}_{t}$ & $0.002(0.008)$ & $-0.007(0.008)$ & $0.007(0.011)$ \\
\hline $\mathrm{DI}^{\mathrm{Nov}} \mathrm{Rain}_{t}$ & $0.001(0.005)$ & $0.007(0.005)$ & $-0.003(0.007)$ \\
\hline $\mathrm{DI}^{\text {Dec }}$ Rain $_{t}$ & $-0.004(0.006)$ & $0.004(0.006)$ & $-0.007(0.008)$ \\
\hline $\mathrm{DI}^{\mathrm{Jan}} \operatorname{Rain}_{t-1}$ & $0.008(0.007)$ & $0.002(0.007)$ & $0.018 *(0.009)$ \\
\hline $\mathrm{DI}^{\mathrm{Feb}} \operatorname{Rain}_{t-1}$ & $-0.009(0.008)$ & $-0.003(0.008)$ & $-0.017(0.010)$ \\
\hline $\mathrm{DI}^{\mathrm{Mar}} \operatorname{Rain}_{t-1}$ & $-0.005(0.011)$ & $0.006(0.011)$ & $-0.014(0.014)$ \\
\hline $\mathrm{DI}^{\mathrm{Apr}} \operatorname{Rain}_{t-1}$ & $0.003(0.009)$ & $0.004(0.009)$ & $0.005(0.012)$ \\
\hline $\mathrm{DI}^{\text {May }} \operatorname{Rain}_{t-1}$ & $0.014^{* *}(0.007)$ & $0.014^{* *}(0.007)$ & $0.013(0.009)$ \\
\hline $\mathrm{DI}^{\mathrm{Jun}} \operatorname{Rain}_{t-1}$ & $-0.008(0.007)$ & $-0.006(0.007)$ & $-0.006(0.009)$ \\
\hline $\mathrm{DI}^{\mathrm{Jul}} \operatorname{Rain}_{t-1}$ & $-0.0003(0.008)$ & $-0.0002(0.008)$ & $-0.001(0.011)$ \\
\hline $\mathrm{DI}^{\mathrm{Aug}} \operatorname{Rain}_{t-1}$ & $0.003(0.006)$ & $0.002(0.006)$ & $0.006(0.008)$ \\
\hline 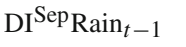 & $-0.002(0.006)$ & $-0.010(0.006)$ & $0.002(0.008)$ \\
\hline $\mathrm{DI}^{\mathrm{Oct}}$ Rain $_{t-1}$ & $-0.017^{*}(0.010)$ & $-0.013(0.009)$ & $-0.020(0.013)$ \\
\hline $\mathrm{DI}^{\text {Nov }}$ Rain $_{t-1}$ & $-0.003(0.008)$ & $-0.009(0.008)$ & $0.002(0.011)$ \\
\hline $\mathrm{DI}^{\mathrm{Dec}} \operatorname{Rain}_{t-1}$ & $0.006(0.005)$ & $0.006(0.005)$ & $0.006(0.006)$ \\
\hline Observations & 176 & 176 & 176 \\
\hline
\end{tabular}


Table 5 continued

\begin{tabular}{llll}
\hline & Dependent variable & & \begin{tabular}{l} 
Nonfood \\
\cline { 2 - 4 }
\end{tabular} \\
\cline { 2 - 4 } & $\begin{array}{l}\text { Total } \\
(1)\end{array}$ & $\begin{array}{l}\text { Food } \\
(2)\end{array}$ \\
\hline$R^{2}$ & 0.495 & 0.337 & 0.500 \\
Adjusted $R^{2}$ & 0.398 & 0.211 & 0.405 \\
\hline
\end{tabular}

${ }^{*} p<0.1 ;{ }^{* *} p<0.05 ;{ }^{* * *} p<0.01$

S.E. are reported in parentheses. Dependent variable $\left(\Delta c_{t}\right)$ is nominal retail trade turnover in $\log$ differences (in percentage). $\Delta c_{t-i}$ denote the lagged dependent variables, $R_{t}=\ln \left(1+r_{t}\right)$, whereas $r_{t}$ is the short-term interest rate, Rain $_{t}$ is the precipitation variable, $\mathrm{DI}^{m}$ is an impulse dummy variable for the month $m$ that takes value of 1 in month $m$ and zero otherwise

Table 6 Month-specific effects of Sunshine

\begin{tabular}{|c|c|c|c|}
\hline & \multicolumn{3}{|l|}{ Dependent variable } \\
\hline & $\begin{array}{l}\text { Total } \\
\text { (1) }\end{array}$ & $\begin{array}{l}\text { Food } \\
(2)\end{array}$ & $\begin{array}{l}\text { Nonfood } \\
\text { (3) }\end{array}$ \\
\hline Constant & $0.003(0.096)$ & $0.087(0.094)$ & $-0.069(0.124)$ \\
\hline$\Delta c_{t-1}$ & $-0.693^{* * *}(0.081)$ & & \\
\hline$\Delta c_{t-2}$ & $-0.472^{* * *}(0.087)$ & & \\
\hline$\Delta c_{t-3}$ & $-0.178^{* *}(0.076)$ & & \\
\hline$\Delta c_{t-1}$ & & $-0.477^{* * *}(0.086)$ & \\
\hline$\Delta c_{t-2}$ & & $-0.278^{* * *}(0.092)$ & \\
\hline$\Delta c_{t-3}$ & & $-0.133(0.083)$ & \\
\hline$\Delta c_{t-1}$ & & & $-0.695^{* * *}(0.079)$ \\
\hline$\Delta c_{t-2}$ & & & $-0.507^{* * *}(0.083)$ \\
\hline$\Delta c_{t-3}$ & & & $-0.234^{* * *}(0.073)$ \\
\hline$R_{t}$ & $0.447^{* * *}(0.128)$ & $0.329^{* * *}(0.124)$ & $0.516^{* * *}(0.164)$ \\
\hline $\operatorname{DISun}_{t}^{\mathrm{Jan}}$ & $-0.001(0.018)$ & $-0.019(0.017)$ & $0.006(0.023)$ \\
\hline $\operatorname{DISun}_{t}^{\mathrm{Feb}}$ & $0.003(0.011)$ & $0.010(0.011)$ & $-0.006(0.014)$ \\
\hline $\operatorname{DISun}_{t}^{\mathrm{Mar}}$ & $0.018^{* *}(0.007)$ & $0.005(0.007)$ & $0.023^{* *}(0.010)$ \\
\hline $\operatorname{DISun}_{t}^{\mathrm{Apr}}$ & $0.011^{*}(0.006)$ & $0.009(0.006)$ & $0.010(0.008)$ \\
\hline $\operatorname{DISun}_{t}^{\text {May }}$ & $-0.005(0.008)$ & $-0.001(0.008)$ & $-0.009(0.011)$ \\
\hline $\operatorname{DISun}_{t}^{\mathrm{Jun}}$ & $-0.005(0.007)$ & $0.007(0.007)$ & $-0.007(0.009)$ \\
\hline $\operatorname{DISun}_{t}^{\mathrm{Jul}}$ & $0.013(0.008)$ & $0.024^{* * *}(0.008)$ & $0.007(0.010)$ \\
\hline $\operatorname{DISun}_{t}^{\mathrm{Aug}}$ & $-0.024^{* * *}(0.007)$ & $0.006(0.007)$ & $-0.039^{* * *}(0.009)$ \\
\hline $\operatorname{DISun}_{t}^{\mathrm{Sep}}$ & $0.002(0.013)$ & $-0.005(0.013)$ & $0.001(0.017)$ \\
\hline $\operatorname{DISun}_{t}^{\text {Oct }}$ & $-0.013(0.015)$ & $0.004(0.015)$ & $-0.019(0.019)$ \\
\hline $\operatorname{DISun}_{t}^{\mathrm{Nov}}$ & $-0.003(0.016)$ & $-0.006(0.016)$ & $-0.005(0.020)$ \\
\hline $\operatorname{DISun}_{t}^{\mathrm{Dec}}$ & $0.0001(0.011)$ & $-0.033^{* * *}(0.011)$ & $0.010(0.014)$ \\
\hline DISun $_{t-1}^{\mathrm{Jan}}$ & $0.008(0.012)$ & $0.008(0.012)$ & $0.012(0.016)$ \\
\hline $\operatorname{DISun}_{t-1}^{\mathrm{Feb}}$ & $0.021(0.018)$ & $0.013(0.017)$ & $0.034(0.023)$ \\
\hline
\end{tabular}


Table 6 continued

\begin{tabular}{llll}
\hline & Dependent variable & & Food \\
\cline { 2 - 4 } & $\begin{array}{l}\text { Total } \\
(1)\end{array}$ & $(2)$ & $\begin{array}{l}\text { Nonfood } \\
(3)\end{array}$ \\
\hline DISun $_{t-1}^{\mathrm{Mar}}$ & $-0.008(0.012)$ & $0.0005(0.012)$ & $-0.010(0.015)$ \\
DISun $_{t-1}^{\text {Apr }}$ & $-0.004(0.007)$ & $-0.005(0.007)$ & $-0.006(0.009)$ \\
DISun $_{t-1}^{\text {May }}$ & $-0.014^{* *}(0.006)$ & $-0.013^{* *}(0.006)$ & $-0.014^{*}(0.008)$ \\
DISun $_{t-1}^{\text {Jun }}$ & $0.002(0.008)$ & $0.001(0.008)$ & $0.005(0.010)$ \\
DISun $_{t-1}^{\text {Jul }}$ & $-0.003(0.007)$ & $-0.006(0.007)$ & $-0.001(0.009)$ \\
DISun $_{t-1}^{\text {Aug }}$ & $0.009(0.008)$ & $-0.002(0.008)$ & $0.012(0.010)$ \\
DISun $_{t-1}^{\text {Sep }}$ & $0.011(0.008)$ & $0.010(0.007)$ & $0.011(0.010)$ \\
DISun $_{t-1}^{\text {Oct }}$ & $0.026^{*}(0.014)$ & $0.002(0.013)$ & $0.043^{* *}(0.018)$ \\
DISun $_{t-1}^{\text {Nov }}$ & $-0.012(0.016)$ & $-0.018(0.016)$ & $-0.004(0.021)$ \\
DISun $_{t-1}^{\text {Dec }}$ & $0.006(0.014)$ & $0.016(0.014)$ & $0.0001(0.018)$ \\
Observations $_{R^{2}}$ & 176 & 176 & 176 \\
Adjusted $^{2}$ & 0.522 & 0.381 & 0.537 \\
\hline
\end{tabular}

${ }^{*} p<0.1 ;{ }^{* *} p<0.05 ;{ }^{* * *} p<0.01$

S.E. are reported in parentheses. Dependent variable $\left(\Delta c_{t}\right)$ is nominal retail trade turnover in log differences (in percentage). $\Delta c_{t-i}$ denote the lagged dependent variables, $R_{t}=\ln \left(1+r_{t}\right)$, whereas $r_{t}$ is the short-term interest rate, $\operatorname{Rain}_{t}$ is the precipitation variable, $\mathrm{DI}^{m}$ is an impulse dummy variable for the month $m$ that takes value of 1 in month $m$ and zero otherwise

The impact of abnormal temperature is also found to be quite similar when the year-on-year growth rates of nominal retail sales are used instead of month-to-month changes (Table 9 in Appendix). In the third robustness check, we control for unemployment rate to make sure that the results are not sensitive for labour market situation. The results are reported in Table 10. In Column (1), the change in unemployment rate, whereas in Column (2), the level of unemployment rate are used. In both cases, the findings concerning the weather effects do not change. Further, we also examine if including exchange rate affects the results. This is not the case as shown in Table 11 in Appendix. 
Table 7 Month-specific effects of temperature-LASSO specification

\begin{tabular}{|c|c|}
\hline Dependent variable & \\
\hline Nominal retail turnover & \\
\hline Constant & $0.030(0.092)$ \\
\hline$\Delta c_{t-1}$ & $-0.602^{* * *}(0.064)$ \\
\hline$\Delta c_{t-2}$ & $-0.338^{* * *}(0.064)$ \\
\hline$R_{t}$ & 0.430 *** $(0.104)$ \\
\hline $\mathrm{DI}^{\mathrm{Mar}} \mathrm{Temp}_{t}$ & $0.591^{* * *}(0.195)$ \\
\hline $\mathrm{DI}^{\mathrm{Apr}} \mathrm{Temp}_{t}$ & $0.220(0.135)$ \\
\hline $\mathrm{DI}^{\mathrm{Jun}} \mathrm{Temp}_{t}$ & $-0.250^{*}(0.128)$ \\
\hline $\mathrm{DI}^{\text {Aug }} \mathrm{Temp}_{t}$ & $-0.628^{* * *}(0.156)$ \\
\hline $\mathrm{DI}^{\text {Sep }} \mathrm{Temp}_{t}$ & $-0.356^{*}(0.181)$ \\
\hline $\mathrm{DI}^{\mathrm{Oct}} \mathrm{Temp}_{t}$ & $-0.646^{* * *}(0.211)$ \\
\hline $\mathrm{DI}^{\mathrm{Nov}} \mathrm{Temp}_{t}$ & $-0.249(0.161)$ \\
\hline $\mathrm{DI}^{\text {May }}$ Temp $_{t-1}$ & $-0.380^{* * *}(0.134)$ \\
\hline $\mathrm{DI}^{\mathrm{Aug}} \mathrm{Temp}_{t-1}$ & $0.252(0.157)$ \\
\hline $\mathrm{DI}^{\mathrm{Sep}} \mathrm{Temp}_{t-1}$ & $0.531^{* * *}(0.159)$ \\
\hline $\mathrm{DI}^{\mathrm{Oct}} \mathrm{Temp}_{t-1}$ & $0.465^{* *}(0.197)$ \\
\hline $\mathrm{DI}^{\text {Nov }} \mathrm{Temp}_{t-1}$ & $0.178(0.201)$ \\
\hline $\mathrm{DI}^{\mathrm{Dec}} \mathrm{Temp}_{t-1}$ & $0.493^{* * *}(0.159)$ \\
\hline Observations & 176 \\
\hline$R^{2}$ & 0.577 \\
\hline Adjusted $R^{2}$ & 0.535 \\
\hline
\end{tabular}

${ }^{*} p<0.1 ;{ }^{* *} p<0.05 ;{ }^{* * *} p<0.01$

S.E. are reported in parentheses. Dependent variable $\left(\Delta c_{t}\right)$ is nominal total retail trade turnover in log differences (in percentage). $\Delta c_{t-i}$ denote the lagged dependent variables, $R_{t}=\ln \left(1+r_{t}\right)$, whereas $r_{t}$ is the short-term interest rate, Rain $_{t}$ is the precipitation variable, $\mathrm{DI}^{m}$ is an impulse dummy variable for the month $m$ that takes value of 1 in month $m$ and zero otherwise 
Table 8 Month-specific effects of temperature-real retail sales

\begin{tabular}{|c|c|c|}
\hline & \multicolumn{2}{|l|}{ Dependent variable } \\
\hline & \multicolumn{2}{|l|}{ Real Retail turnover } \\
\hline & (1) & (2) \\
\hline Constant & $0.284^{* * *}(0.097)$ & $0.245^{* * *}(0.084)$ \\
\hline$\Delta c_{t-1}$ & $-0.741^{* * *}(0.076)$ & $-0.596^{* * *}(0.070)$ \\
\hline$\Delta c_{t-2}$ & $-0.493^{* * *}(0.088)$ & $-0.372^{* * *}(0.079)$ \\
\hline$\Delta c_{t-3}$ & $-0.171^{* *}(0.078)$ & $-0.099(0.070)$ \\
\hline$R_{t}$ & $0.258^{*}(0.152)$ & $0.282^{* *}(0.133)$ \\
\hline $\mathrm{DTI}^{\mathrm{Jan}} \mathrm{Temp}_{t}$ & & $0.175(0.128)$ \\
\hline $\mathrm{DTI}^{\mathrm{Feb}} \mathrm{Temp}_{t}$ & & $0.095(0.091)$ \\
\hline $\mathrm{DTI}^{\mathrm{Mar}} \mathrm{Temp}_{t}$ & & $0.367^{* *}(0.150)$ \\
\hline $\mathrm{DTI}^{\mathrm{Apr}} \mathrm{Temp}_{t}$ & & $0.334^{* * *}(0.102)$ \\
\hline 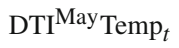 & & $-0.059(0.145)$ \\
\hline $\mathrm{DTI}^{\mathrm{Jun}} \mathrm{Temp}_{t}$ & & $-0.146(0.097)$ \\
\hline $\mathrm{DTI}^{\mathrm{Jul}} \mathrm{Temp}_{t}$ & & $-0.069(0.116)$ \\
\hline $\mathrm{DTI}^{\mathrm{Aug}} \mathrm{Temp}_{t}$ & & $-0.559^{* * *}(0.117)$ \\
\hline $\mathrm{DTI}^{\text {Sep }} \mathrm{Temp}_{t}$ & & $-0.366^{* * *}(0.135)$ \\
\hline $\mathrm{DTI}^{\mathrm{Oct}} \mathrm{Temp}_{t}$ & & $-0.413^{* * *}(0.149)$ \\
\hline $\mathrm{DTI}^{\mathrm{Nov}} \mathrm{Temp}_{t}$ & & $-0.413^{* * *}(0.120)$ \\
\hline $\mathrm{DTI}^{\mathrm{Dec}} \mathrm{Temp}_{t}$ & & $0.108(0.135)$ \\
\hline Observations & 173 & 173 \\
\hline$R^{2}$ & 0.368 & 0.561 \\
\hline Adjusted $R^{2}$ & 0.352 & 0.516 \\
\hline
\end{tabular}

${ }^{*} p<0.1 ;{ }^{* *} p<0.05 ;{ }^{* * *} p<0.01$

S.E. are reported in parentheses. Dependent variable $\left(\Delta c_{t}\right)$ is real total retail trade turnover in log differences (in percentage points). $\Delta c_{t-i}$ denote the lagged dependent variables, $R_{t}=\ln \left(1+r_{t}\right)$ whereas $r_{t}$ is the short-term interest rate, $\mathrm{Temp}_{t}$ is the temperature variable, $\mathrm{DTI}^{m}$ is a transitional impulse dummy variable taking 1 in month $m$ and -1 in the following month. and zero otherwise 
Table 9 Month-specific effects of temperature-year-on-year growth rates

\begin{tabular}{|c|c|c|}
\hline & \multicolumn{2}{|l|}{ Dependent variable } \\
\hline & \multicolumn{2}{|c|}{ Nominal retail turnover (yoy) } \\
\hline & (1) & (2) \\
\hline Constant & $0.350^{* *}(0.144)$ & $0.305^{* *}(0.140)$ \\
\hline$\Delta^{12} c_{t-1}$ & $0.108(0.077)$ & $0.211^{* * *}(0.080)$ \\
\hline$\Delta^{12} c_{t-2}$ & $0.146^{*}(0.076)$ & $0.113(0.078)$ \\
\hline$\Delta^{12} c_{t-3}$ & $0.229^{* * *}(0.076)$ & $0.224^{* * *}(0.076)$ \\
\hline$\Delta^{12} c_{t-12}$ & $-0.185^{* * *}(0.063)$ & $-0.170^{* * *}(0.063)$ \\
\hline$R_{t}$ & $1.367^{* * *}(0.255)$ & $1.220 * * *(0.250)$ \\
\hline $\mathrm{DTI}^{\mathrm{Jan}} \mathrm{Temp}_{t}$ & & $0.016(0.184)$ \\
\hline $\mathrm{DTI}^{\mathrm{Feb}} \mathrm{Temp}_{t}$ & & $0.141(0.136)$ \\
\hline $\mathrm{DTI}^{\mathrm{Mar}} \mathrm{Temp}_{t}$ & & $0.602^{* * *}(0.223)$ \\
\hline $\mathrm{DTI}^{\mathrm{Apr}} \mathrm{Temp}_{t}$ & & $0.301^{* *}(0.142)$ \\
\hline DTI $^{\text {May }}$ Temp $_{t}$ & & $0.201(0.214)$ \\
\hline DTI $^{\text {Jun }}$ Temp $_{t}$ & & $0.163(0.252)$ \\
\hline $\mathrm{DTI}^{\mathrm{Jul}} \mathrm{Temp}_{t}$ & & $-0.002(0.172)$ \\
\hline DTI $^{\text {Aug } \text { Temp }_{t}}$ & & $-0.189(0.213)$ \\
\hline $\mathrm{DTI}^{\mathrm{Sep}} \mathrm{Temp}_{t}$ & & $-0.496^{* *}(0.200)$ \\
\hline $\mathrm{DTI}^{\mathrm{Oct}} \mathrm{Temp}_{t}$ & & $-0.419^{*}(0.235)$ \\
\hline DTI $^{\text {Nov }}$ Temp $_{t}$ & & $-0.343^{*}(0.185)$ \\
\hline $\mathrm{DTI}^{\mathrm{Dec}} \mathrm{Temp}_{t}$ & & $-0.241(0.204)$ \\
\hline Observations & 156 & 156 \\
\hline$R^{2}$ & 0.589 & 0.648 \\
\hline Adjusted $R^{2}$ & 0.575 & 0.605 \\
\hline
\end{tabular}

${ }^{*} p<0.1 ;{ }^{* *} p<0.05 ;{ }^{* * *} p<0.01$

S.E. are reported in parentheses. Dependent variable $\left(\Delta^{12} c_{t}\right)$ is total nominal retail trade turnover in log annual differences (in percentage points). $\Delta^{12} c_{t-i}$ denote the lagged dependent variables, $R_{t}=\ln (1+$ $r_{t}$ ) whereas $r_{t}$ is the short-term interest rate, Temp $\mathrm{P}_{t}$ is the temperature variable, $\mathrm{DTI}^{m}$ is a transitional impulse dummy variable taking 1 in month $m$ and -1 in the following month. and zero otherwise 
Table 10 Month-specific effects of temperature with unemployment rate

\begin{tabular}{|c|c|c|}
\hline & \multicolumn{2}{|l|}{ Dependent variable } \\
\hline & \multicolumn{2}{|c|}{ Nominal Retail turnover } \\
\hline & (1) & (2) \\
\hline Constant & $0.044(0.082)$ & $-0.660(0.714)$ \\
\hline$\Delta c_{t-1}$ & $-0.605^{* * *}(0.069)$ & $-0.608^{* * *}(0.069)$ \\
\hline$\Delta c_{t-2}$ & $-0.408^{* * *}(0.078)$ & $-0.410^{* * *}(0.078)$ \\
\hline$\Delta c_{t-3}$ & $-0.127^{*}(0.068)$ & $-0.128^{*}(0.068)$ \\
\hline$R_{t}$ & $0.384^{* * *}(0.104)$ & $0.450^{* * *}(0.120)$ \\
\hline$\Delta u_{t}$ & $-1.058(1.567)$ & \\
\hline$u_{t}$ & & $0.228(0.233)$ \\
\hline $\mathrm{DTI}^{\mathrm{Jan}} \mathrm{Temp}_{t}$ & $0.181(0.124)$ & $0.179(0.124)$ \\
\hline $\mathrm{DTI}^{\mathrm{Feb}} \mathrm{Temp}_{t}$ & $0.103(0.088)$ & $0.104(0.088)$ \\
\hline $\mathrm{DTI}^{\mathrm{Mar}} \mathrm{Temp}_{t}$ & $0.352^{* *}(0.143)$ & $0.351^{* *}(0.143)$ \\
\hline $\mathrm{DTI}^{\mathrm{Apr}} \mathrm{Temp}_{t}$ & $0.298^{* * *}(0.097)$ & $0.299^{* * *}(0.097)$ \\
\hline DTI $^{\text {May }} \mathrm{Temp}_{t}$ & $-0.054(0.138)$ & $-0.042(0.138)$ \\
\hline DTI $^{\text {Jun }}$ Temp $_{t}$ & $-0.165^{*}(0.094)$ & $-0.166^{*}(0.094)$ \\
\hline $\mathrm{DTI}^{\mathrm{Jul}} \mathrm{Temp}_{t}$ & $-0.093(0.113)$ & $-0.093(0.113)$ \\
\hline $\mathrm{DTI}^{\mathrm{Aug}} \mathrm{Temp}_{t}$ & $-0.564^{* * *}(0.114)$ & $-0.560^{* * *}(0.114)$ \\
\hline $\mathrm{DTI}^{\mathrm{Sep}} \mathrm{Temp}_{t}$ & $-0.334^{* *}(0.131)$ & $-0.336^{* *}(0.131)$ \\
\hline $\mathrm{DTI}^{\mathrm{Oct}} \mathrm{Temp}_{t}$ & $-0.423^{* * *}(0.143)$ & $-0.423^{* * *}(0.143)$ \\
\hline $\mathrm{DTI}^{\mathrm{Nov}} \mathrm{Temp}_{t}$ & $-0.376^{* * *}(0.116)$ & $-0.374^{* * *}(0.116)$ \\
\hline $\mathrm{DTI}^{\mathrm{Dec}} \mathrm{Temp}_{t}$ & $0.091(0.131)$ & $0.091(0.131)$ \\
\hline Observations & 176 & 176 \\
\hline$R^{2}$ & 0.574 & 0.575 \\
\hline Adjusted $R^{2}$ & 0.528 & 0.530 \\
\hline
\end{tabular}

${ }^{*} p<0.1 ;{ }^{* *} p<0.05 ;{ }^{* * *} p<0.01$

S.E. are reported in parentheses. Dependent variable $\left(\Delta c_{t}\right)$ is nominal total retail trade turnover in log differences (in percentage). $\Delta c_{t-i}$ denote the lagged dependent variables, $R_{t}=\ln \left(1+r_{t}\right)$, whereas $r_{t}$ is the short-term interest rate, $u_{t}$ is the unemployment rate, $\Delta u_{t}$ is changes in the unemployment rate, $\mathrm{Temp}_{t}$ is the temperature variable, $\mathrm{DTI}^{m}$ is a transitional impulse dummy variable taking 1 in month $m$ and -1 in the following month and zero otherwise 
Table 11 Month-specific effects of Temperature with exchange rate

\begin{tabular}{|c|c|c|}
\hline & \multicolumn{2}{|l|}{ Dependent variable } \\
\hline & \multicolumn{2}{|c|}{ Nominal Retail turnover (dl) } \\
\hline & (1) & (2) \\
\hline Constant & $0.053(0.081)$ & $-0.579(1.087)$ \\
\hline$\Delta c_{t-1}$ & $-0.591^{* * *}(0.069)$ & $-0.604^{* * *}(0.069)$ \\
\hline$\Delta c_{t-2}$ & $-0.395^{* * *}(0.077)$ & $-0.407^{* * *}(0.078)$ \\
\hline$\Delta c_{t-3}$ & $-0.130 *(0.068)$ & $-0.125^{*}(0.068)$ \\
\hline$R_{t}$ & $0.370^{* * *}(0.104)$ & $0.294(0.198)$ \\
\hline$\Delta E x c R_{t}$ & $0.087(0.055)$ & \\
\hline$E x c R_{t}$ & & $0.457(0.806)$ \\
\hline $\mathrm{DTI}^{\mathrm{Jan}} \mathrm{Temp}_{t}$ & $0.165(0.124)$ & $0.181(0.124)$ \\
\hline $\mathrm{DTI}^{\mathrm{Feb}} \mathrm{Temp}_{t}$ & $0.094(0.087)$ & $0.104(0.088)$ \\
\hline $\mathrm{DTI}^{\mathrm{Mar}} \mathrm{Temp}_{t}$ & $0.362^{* *}(0.142)$ & $0.353^{* *}(0.143)$ \\
\hline $\mathrm{DTI}^{\mathrm{Apr}} \mathrm{Temp}_{t}$ & $0.288^{* * *}(0.097)$ & $0.300^{* * *}(0.097)$ \\
\hline 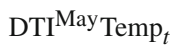 & $-0.041(0.137)$ & $-0.045(0.138)$ \\
\hline DTI $^{\text {Jun }}$ Temp $_{t}$ & $-0.166^{*}(0.093)$ & $-0.166^{*}(0.094)$ \\
\hline $\mathrm{DTI}^{\mathrm{Jul}} \mathrm{Temp}_{t}$ & $-0.078(0.113)$ & $-0.093(0.113)$ \\
\hline DTI $^{\text {Aug }}$ Temp $_{t}$ & $-0.545^{* * *}(0.114)$ & $-0.561^{* * *}(0.114)$ \\
\hline $\mathrm{DTI}^{\text {Sep }} \mathrm{Temp}_{t}$ & $-0.352^{* * *}(0.130)$ & $-0.336^{* *}(0.131)$ \\
\hline $\mathrm{DTI}^{\mathrm{Oct}} \mathrm{Temp}_{t}$ & $-0.434^{* * *}(0.143)$ & $-0.424^{* * *}(0.143)$ \\
\hline $\mathrm{DTI}^{\mathrm{Nov}} \mathrm{Temp}_{t}$ & $-0.388^{* * *}(0.115)$ & $-0.375^{* * *}(0.116)$ \\
\hline $\mathrm{DTI}^{\mathrm{Dec}} \mathrm{Temp}_{t}$ & $0.071(0.131)$ & $0.096(0.131)$ \\
\hline Observations & 176 & 176 \\
\hline$R^{2}$ & 0.580 & 0.574 \\
\hline Adjusted $R^{2}$ & 0.534 & 0.528 \\
\hline
\end{tabular}

${ }^{*} p<0.1 ;{ }^{* *} p<0.05 ;{ }^{* * *} p<0.01$

S.E. are reported in parentheses. Dependent variable $\left(\Delta c_{t}\right)$ is nominal total retail trade turnover in log differences (in percentage). $\Delta c_{t-i}$ denote the lagged dependent variables, $R_{t}=\ln \left(1+r_{t}\right)$, whereas $r_{t}$ is the short-term interest rate, $\Delta \mathrm{ExcR}_{t}$ is the change of real exchange rate index, ExcR $t$ is the real exchange rate index, Temp $_{t}$ is the temperature variable, $\mathrm{DTI}^{m}$ is a transitional impulse dummy variable taking 1 in month $m$ and -1 in the following month and zero otherwise 


\section{References}

Baker D (2012) Making heavy weather on economic forecasting. https://www.theguardian.com/ commentisfree/cifamerica/2012/apr/26/making-heavy-weather-economic-forecasting. The Guardian

Beniston M, Stephenson DB, Christensen OB, Ferro CAT, Frei C, Goyette S, Halsnaes K, Holt T, Jylhä K, Koffi B, Palutikof J, Schöll R, Semmler T, Woth K (2007) Future extreme events in European climate: an exploration of regional climate model projections. Clim Change 81(SUPPL. 1):71-95

Boldin M, Wright JH (2015) Weather-adjusting economic data. Brook Papers Econ Act 2:227-278

Breiman L (2001) Random forests. Mach Learn 45(1):5-32

Busse MR, Pope DG, Pope JC, Silva-Risso J (2015) The psychological effect of weather on car purchases. Q J Econ 130(1):371-414

Goulet CP (2020) The macroeconomy as a random forest. https://arxiv.org/abs/2006.12724

Hendry D, Juselius K (2001) Explaining cointegration analysis: part II. Energy J 22(1):75-120

Jakob D, Walland D (2016) Variability and long-term change in Australian temperature and precipitation extremes. Weather Clim Extremes 14:36-55

Linden F (1962) Consumer markets: merchandising weather. Conf Board Bus Record 19(6):15-16

Maunder W (1973) Weekly weather and economic activities on a national scale: an example using United States retail trade data. Weather 28(1):2-19

McQuigg J (1972) The use of meteorological information in economic development. Technical report

Murray KB, Di Muro F, Finn A, Popkowski Leszczyc P (2010) The effect of weather on consumer spending. J Retail Consum Serv 17(6):512-520

Siliverstovs B, Ötsch R, Kemfert C, Jaeger CC, Haas A, Kremers H (2010) Climate change and modelling of extreme temperatures in Switzerland. Stoch Environ Res Risk Assess 24(2):311-326

Starr-McCluer M (2000) The effects of weather on retail sales. Divisions of Research and Statistics and Monetary Affairs, Federal Reserve Board, New York

Publisher's Note Springer Nature remains neutral with regard to jurisdictional claims in published maps and institutional affiliations.

\section{Affiliations}

\section{Anna Pauliina Sandqvist ${ }^{1}$ - Boriss Siliverstovs ${ }^{2,3}$}

$凶$ Anna Pauliina Sandqvist

sandqvist@ifo.de

Boriss Siliverstovs

boriss.siliverstovs@bank.lv

1 ifo Institute - Leibniz Institute for Economic Research at the University of Munich,

Poschingerstrasse 5, 81679 Munich, Germany

2 Latvijas Banka, Kr. Valdemara 2a, Riga 1050, Latvia

3 KOF Research Affiliate, ETH Zurich, KOF Swiss Economic Institute, Zurich, Switzerland 